\title{
AVALIAÇÃO DA TEMPORALIDADE DE OCUPAÇÕES EM ÁREAS DE PRESERVAÇÃO PERMANENTE NO MUNICÍPIO DE JUNDIAÍ/SP
}

\author{
EVALUATION OF TEMPORALITY ON THE OCCUPATION IN PERMANENT \\ PRESERVATION AREAS IN THE MUNICIPALITY OF JUNDIAÍ/SP
}

Felipe Rosafa Gavioli ${ }^{1}$, Amanda Maria Tavares Hossomi²

\section{RESUMO}

As Áreas de Preservação Permanente (APPs) são áreas protegidas, definidas pela legislação e que devem ser mantidas com vegetação nativa. As metragens e a definição das APPs foram sendo modificadas ao longo dos anos, desde a publicação do código florestal de 1965, que teve diversas alterações até sua atual versão dada pela publicação da Lei 12.651/2012. A Companhia Ambiental do Estado de São Paulo (CETESB) utiliza estas mudanças históricas da legislação para avaliar a regularização de usos antrópicos consolidados em locais que hoje são considerados como APPs, a partir da temporalidade da ocupação. O presente estudo avaliou a temporalidade das ocupações existentes em APPs hídricas em 2018, identificando quais destas ocupações são anteriores a 1986, no município de Jundiaí/SP, a partir de técnicas de geoprocessamento. Identificou-se que dos 8.390 hectares de APPs hídricas do município, 625,86 hectares estavam ocupados em 2018 por usos antrópicos exceto agropecuária. Deste montante, 303,67 hectares podem ter o uso antrópico regularizado, já que a ocupação existe desde 1985, quando tais áreas não eram consideradas como APPs. Entre 1985 e 2018, houve incremento de cobertura florestal em 214,97 hectares de APPs. O uso de geoprocessamento pode auxiliar os órgãos competentes na gestão e no licenciamento ambiental.

Palavras-chave: Geoprocessamento, Código Florestal, uso e cobertura do solo, iniciativa MapBiomas, licenciamento ambiental.

\begin{abstract}
Permanent Preservation Areas (APPs) are protected areas, defined by legislation and must be maintained with native vegetation. The lengths and the definition of APPs have been modified over the years, since the publication of the forest code in 1965, which had several changes until its actual version with the publication of the Law 12.651/2012. The Environmental Company of the State of São Paulo (CETESB) uses these historical changes in legislation to assess the regularization of consolidated anthropic uses in areas that today are considered as APPs, based on the temporality of the occupation. This study evaluated the temporality of existing occupations in riparian APPs in 2018, identifying which of these occupations are prior to 1986, in the municipality of Jundiaí/SP, using geoprocessing techniques. It was identified that of the 8,390 hectares of riparian APPs in the municipality, 625.86 hectares were occupied in 2018 by anthropic uses except for agriculture. Of this amount, 303.67 hectares can be regularized, once the occupation has existed since 1985 when such areas were not considered as APPs. Between 1985 and 2018, there was an increase in forest cover in 214.97 hectares of APPs. The use of geoprocessing tools can assist the environmental agencies in environmental management and licensing.
\end{abstract}

Keywords: Geoprocessing, Forest Code, land use and land cover, MapBiomas initiative, environmental licensing.

Recebido em 27.01.2020 e aceito em 24.07.2020

1 Engenheiro Agrônomo, doutorando em Planejamento e Uso de Recursos Renováveis. Engenheiro da Companhia Ambiental do Estado de São Paulo (CETESB). Jundiaí/SP. Email: gavioli.f@gmail.com

2 Engenheira Ambiental, especialista em Gerenciamento Ambiental. Engenheira da Companhia Ambiental do Estado de São Paulo (CETESB). Jundiaí/SP. Email: ahossomi@gmail.com

${ }^{*}$ As opiniões, entendimentos e conclusões deste texto são de responsabilidade exclusiva dos autores e não reflete, necessariamente, o entendimento da Companhia Ambiental do Estado de São Paulo - CETESB. 


\section{INTRODUÇÃO}

A conservação e a restauração de florestas em paisagens antropizadas é estratégia central para a promoção de diversos serviços ecossistêmicos de interesse econômico e social, tais como a regulação climática, a estocagem de carbono, a manutenção da biodiversidade, a produção de água em quantidade e qualidade, dentre outros (SCHMIDT et al., 2019).

Um dos principais instrumentos legais para a promoção da conservação e da restauração de florestas no Brasil é a Lei de Proteção da Vegetação Nativa (LPVN), consubstanciada na Lei Federal 12.651, de 25 de maio de 2012, com alterações dadas pela Lei Federal 12.727, de 17 de outubro de 2012, e regulamentada pelo Decreto 7.830, de 17 de outubro de 2012 (AGUIAR et al., 2017). A LPVN opera a partir do estabelecimento de duas categorias de áreas especialmente protegidas que incidem nas propriedades privadas do país, a saber, as áreas de Reserva Legal e as Áreas de Preservação Permanente (APPs).

Estas últimas são definidas pela legislação como áreas de ocupação restrita, aplicáveis tanto em propriedades urbanas quanto em imóveis rurais, e instituídas em faixa variável ao longo dos rios e córregos, no entorno de nascentes e de determinadas categorias de lagos ou represamentos de água, em áreas de elevada declividade, dentre outras áreas frágeis do ponto de vista ambiental ou geotécnico (BRASIL, 2012). As APPs precisam ser mantidas com vegetação florestal ou nativa, conforme determina o artigo $7^{\circ}$ da LPVN, sendo que a ocupação ou intervenção em APP é admitida excepcionalmente nos casos de utilidade pública, interesse social, ou baixo impacto ambiental (BRASIL, 2012).

Em relação às chamadas APPs hídricas, isto é, aquelas associadas a corpos hídricos, nascentes ou lagos/barramentos, a LPVN define que para os cursos d'água de até 10 metros de largura a faixa protegida a título de preservação permanente é de 30 metros; e para os corpos hídricos com largura entre 10 e 50 metros a faixa protegida é de 50 metros. No entorno das nascentes a APP é definida em raio de 50 metros e para lagos/represas a faixa protegida é variável conforme a tipologia da massa de água (se natural, decorrente de barramento ou de escavação), tamanho do espelho d'água, e localização em perímetro rural ou urbano.

A manutenção das APPs hídricas com vegetação florestal ripária é fundamental para o adequado desempenho das funções eco-hidrológicas destas áreas, tais como a retenção de sedimentos oriundos do escoamento superficial, a diminuição da velocidade da água com proteção das margens dos córregos contra desbarrancamentos, a melhoria na infiltração da água, a conservação de biodiversidade, entre outros (TAMBOSI et al., 2015). A proteção das APPs associadas aos córregos de primeira ordem ganha ainda mais relevância, pelo fato destes apresentarem, no geral, água de melhor qualidade e por serem mais susceptíveis a degradação por processos de assoreamento (TANIWAKI et al., 2018). 
No contexto da expansão urbana, a manutenção de boas condições de preservação das Áreas Verdes, dentre estas as APPs, produz diversos benefícios como conforto térmico, regulação do microclima, diminuição da poluição atmosférica e sonora, melhoria dos aspectos estéticos e paisagísticos da malha urbana, criação de espaços para recreação e contato com a natureza, dentre outros que contribuem para a construção de cidades saudáveis (AGUJARO; COLLAÇO; PINTO, 2018).

Em que pese a necessidade de manter estas áreas efetivamente protegidas e florestadas, observa-se que em muitos casos, em especial nas cidades brasileiras, as APPs hídricas se apresentam degradadas e ocupadas por estruturas urbanas. Estudo de Silva Neto e Aleixo (2019) identificou que um terço das APPs hídricas da cidade de Manaus/AM estavam degradadas em 2017. Silva, Guimarães e Oliveira (2017), utilizando imagens de satélite de 2009 e 2013, verificaram que 65\% das APPs da zona urbana de Porto Velho/RO estão antropizadas. Na cidade de Ouro Preto/MG, 19\% das APPs se encontravam antropizadas em 2011 (LUCON et al., 2011). Em Indaiatuba, interior do estado de São Paulo, 20,56\% das APPs estavam degradadas com edificações, solo exposto e estruturas urbanas em 2015 (ARAÚJO, 2015).

Em alguns casos, as situações de uso antrópico das APPs no contexto urbano estão consolidadas há anos, e além de serem de difícil reversão, podem ser passíveis de regularização. Isto porque as metragens de proteção associadas às APPs, e a própria definição de APP, foram sendo modificadas ao longo dos anos desde a publicação do primeiro código florestal em 1934, passando pelo código florestal de 1965, que teve diversas alterações significativas até sua revogação com a publicação da versão atual da legislação dada pela Lei 12.651/2012 .

Neste histórico, têm-se que de 1965, ano da publicação do código florestal por meio da Lei 4.771, até a alteração dada pela publicação da Lei Federal 7.511 em 07 de julho de 1986, as APPs dos cursos d'água eram assim definidas (BRASIL, 1965):

"Art. $2^{\circ}$ Consideram-se de preservação permanente, pelo só efeito desta Lei, as florestas e demais formas de vegetação natural situadas:

a) ao longo dos rios ou de outro qualquer curso d'água, em faixa marginal cuja largura mínima será:

1. de 5 (cinco) metros para os rios de menos de 10 (dez) metros de largura;

2. igual à metade da largura dos cursos que meçam de 10 (dez) a 200 (duzentos) metros de distância entre as margens;"

Verifica-se que a Lei 4.771/1965 garantia proteção em faixa de 05 metros para corpos hídricos de até 10 metros de largura, e tutelava somente a flora, ou seja, faixas não ocupadas por vegetação nativa não estavam protegidas no marco deste diploma legal, Ademais, o texto original da Lei 4.771/1965 não se aplicava às zonas urbanas (AZEVEDO; OLIVEIRA, 2014). 
No caso das nascentes e lagos/represamentos de água, a Lei 4.771/1965 não delimitava qualquer faixa protetiva à título de Área de Preservação Permanente, o que ocorre somente a partir de 1986, através da publicação da Resolução CONAMA 004/1985 (BRASIL, 1965; BRASIL 1986a).

Ainda em 1986, houve a publicação da Lei Federal 7.511, a partir da qual a APP passou a ser considerada de 30 metros para corpos hídricos de até 10 metros de largura e de 50 metros para rios com largura entre 10 e 50 metros, bem como foi definido raio de proteção de 50 metros no entorno de nascentes. No caso das massas de água, a Resolução CONAMA 004, de 18 de setembro de 1985 estabeleceu APPs variáveis de 30 a 100 metros, a depender do tamanho do espelho d'água e localização (se em zona rural ou urbana) (BRASIL, 1986a; BRASIL, 1986b).

Ainda, verifica-se que a partir da publicação da Lei Federal 7.803 em 18 de julho de 1989, a faixa de preservação permanente associada a corpos hídricos passou a ser considerada desde o nível mais alto do curso d'água, incluindo, deste modo, as áreas de várzea (BRASIL, 1989), o que foi alterado pela LPVN, por meio da qual a faixa de preservação permanente retornou a ser mensurada a partir da calha regular dos cursos d'água, deixando desprotegidas as áreas de várzea e de inundação sazonal.

Estas modificações ocorridas ao longo do tempo na delimitação das faixas de preservação permanente hídricas apresentam impactos relevantes nas ações de gestão e de licenciamento ambiental conduzidas pelos órgãos gestores. No Estado de São Paulo, a Companhia Ambiental do Estado de São Paulo - CETESB, órgão responsável pela gestão e licenciamento ambiental, utiliza o princípio da temporalidade na avaliação de ocupações e usos das APPs que não podem ser enquadrados como de utilidade pública, interesse social, ou baixo impacto ambiental, e que, portanto, estão em desacordo com a legislação atualmente vigente.

A partir da noção de temporalidade, consideram-se como regulares as ocupações realizadas até 1986 nas faixas que hoje são APP, desde que respeitada a APP vigente à época de sua implantação. Neste caso, as ocupações são passíveis de continuidade, possuindo os proprietários o direito ao uso. Desta forma, uma edificação que se encontra a 20 metros do curso d'agua, ou no interior do raio de 50 metros projetado a partir de nascente, por exemplo, é considerada regular pelo órgão ambiental se comprovado que tal edificação foi implantada antes de 1986, quando a área ainda não era considerada como de preservação permanente, com as restrições de uso associadas a esta classificação.

Neste cenário, estimativas das APPs hídricas degradadas, isto é, desprovidas de vegetação nativa e, portanto, passíveis de restauração ecológica, existentes em determinado território podem ser impactadas pela aplicação do princípio da temporalidade, especialmente em regiões densamente urbanizadas. Deste modo, conhecer as áreas hoje consideradas como APPs que foram ocupadas/edificadas em período anterior a esta categorização permite estimar, 
em um ajuste mais fino, o montante de APPs degradadas cuja restauração ecológica deverá ser compulsória em determinado território, bem como ilumina os processos de ocupação irregular (pós-1986) destas áreas especialmente protegidas.

Uma análise desta natureza para um território amplo pode ser realizada a partir de uso de geoprocessamento e de bases de dados disponíveis ao público. O presente estudo se insere neste contexto e busca, a partir do uso de informações geoespaciais disponibilizadas pela iniciativa MapBiomas e pela Fundação Brasileira de Desenvolvimento Sustentável (FBDS), efetuar uma estimativa do montante de APPs ocupadas de forma regular pelo princípio da temporalidade; bem como identificar os principais vetores de mudança no uso e cobertura do solo destas áreas especialmente protegidas no município de Jundiaí/SP.

O município de Jundiaí foi selecionado para este estudo por possuir urbanização antiga, com processo de expansão acelerado em decorrência da sua malha viária (PRADELA; BUENO, 2017). Ademais, é um município industrializado de médio porte, que pode representar a realidade de parcela importante dos municípios do interior paulista.

Assim, o objetivo geral deste trabalho foi realizar o levantamento das informações de uso e ocupação do solo nas APPs hídricas, associadas a nascentes, massas de água e cursos d'água existentes no município de Jundiaí, definidas conforme a Lei Federal 12.651/12, utilizando os dados geoespaciais disponíveis ao público no banco de dados da coleção 4.0 da iniciativa MapBiomas e FBDS, visando verificar as APPs que se encontram regularmente ocupadas, para as quais existe direito de uso em decorrência da temporalidade. Tal levantamento poderá servir como ferramenta para os órgãos municipais e estadual para a avaliação da possibilidade de manutenção das ocupações. A partir deste objetivo geral, o estudo busca resposta aos seguintes objetivos específicos:

- Avaliar as condições de uso e cobertura do solo nas APPs hídricas de Jundiaí em 1985 e em 2018.

- Averiguar a tendência de mudança de uso e cobertura do solo nestas áreas entre os períodos estudados, como desmatamento e ocupação, ou restauração ecológica.

- Verificar o montante de APPs ocupadas em 1985 que permaneceram ocupadas em 2018, e que, portanto, podem requerer reconhecimento de regularidade pela temporalidade.

- Estimar o montante de APPs sem cobertura de vegetação florestal ou nativa, e sem ocupações passíveis de regularização pelo princípio da temporalidade e que constituem o universo de APPs passíveis de receberem projetos de restauração ecológica ${ }^{3}$.

\footnotetext{
${ }^{3}$ Neste estudo não foi efetuado modelagem da aplicação do artigo 61-A da Lei 12.651/2012, que instituiu a flexibilização da recomposição florestal de APPs em imóveis rurais com uso rural consolidado em APP anterior a julho.2008 (a chamada "regra da escadinha"). Do universo de APPs sem ocupação regular pelo princípio da temporalidade, e sem cobertura de vegetação nativa, provavelmente existem APPs ocupadas por atividade agrossilvipastoril anterior a 2008, ao que a recomposição seria variável em função do tamanho do imóvel rural, conforme estabelece o artigo 61-A em referência.
} 


\section{MATERIAIS E MÉTODOS}

O estudo foi realizado no município de Jundiaí, interior do estado de São Paulo. Localizado a cerca de 60 quilômetros da capital paulista, Jundiaí apresenta área total de 43.121,00 hectares, e população estimada para o ano de 2020 em 407 mil habitantes. Cerca de $97 \%$ da população vive na zona urbana do município, e a economia é fortemente vinculada ao setor serviços (cerca de $75 \%$ do produto interno bruto municipal) e também ao setor industrial, responsável por quase $25 \%$ do produto interno bruto municipal (SEADE, 2020).

Em que pese a característica urbana do município, Jundiaí abriga em cerca de um terço do seu território o maciço montanhoso da Serra do Japi, um importante remanescente florestal da Mata Atlântica paulista (MORELATTO, 1992). Com vistas a proteger esta área florestada, o município se tornou uma Unidade de Conservação de Uso Sustentável, da categoria Área de Proteção Ambiental (APA) em 1984. A Figura 1 apresenta um mapa de localização do município de Jundiaí.

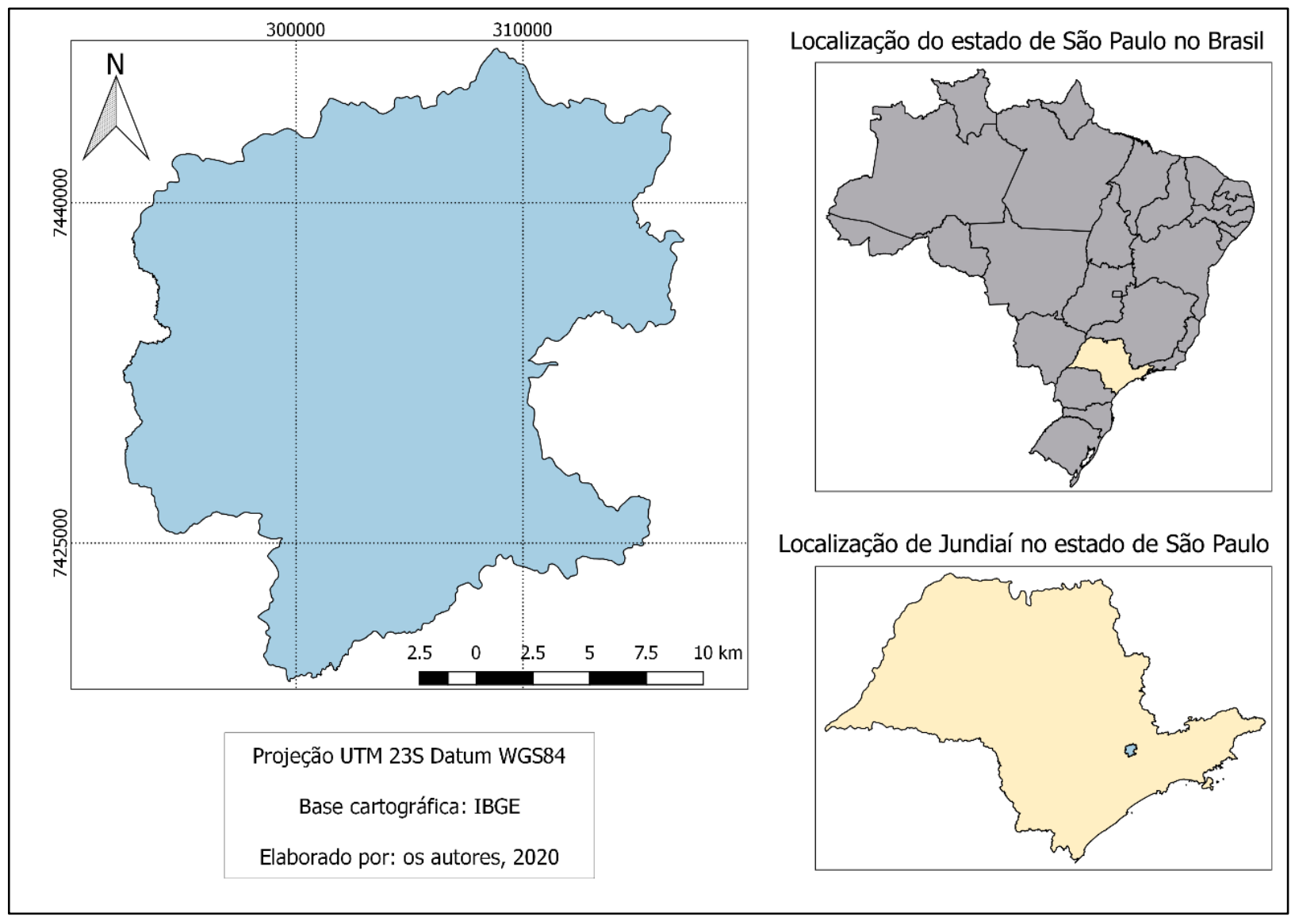

Figura 1. Mapa de localização do município de Jundiaí/SP

Figure 1. Location map of the municipality of Jundiaí/SP

Para a realização do estudo, inicialmente foi acessada a base de dados pública da FBDS, disponível em http://geo.fbds.org.br/SP/, para obtenção dos arquivos vetoriais (formato 
shapefile) das APPs hídricas do município de Jundiaí, delimitadas conforme a Lei 12.651/2012. Estes arquivos foram gerados no âmbito do projeto "Mapeamento em Alta Resolução dos Biomas Brasileiros" elaborado pela FBDS que produziu dados primários de uso e cobertura do solo, rede hidrográfica e APPs para todos os municípios brasileiros a partir do tratamento de imagens do satélite RapidEye com resolução de 05 metros, objetivando apoiar a implementação do Cadastro Ambiental Rural no território nacional (FBDS, 2018; REZENDE et al., 2018).

Após, foi acessada a base de dados da Coleção 4.0 da iniciativa MapBiomas a partir dos scripts disponibilizados na plataforma Google Earth Engine, com acesso por meio do link https://code.earthengine.google.com/.

O MapBiomas - Projeto de Mapeamento Anual da Cobertura e Uso do Solo no Brasil é uma iniciativa interinstitucional lançada em 2015 que objetiva efetuar o mapeamento anual de uso e cobertura do solo em todo o território brasileiro, com dados disponíveis a partir do ano de 1985. Os mapeamentos realizados pela iniciativa MapBiomas são elaborados a partir de imagens de satélite, com resolução espacial máxima de 30 metros, permitindo uma análise detalhada das classes de uso e cobertura do solo que envolvem, por exemplo, a vegetação natural (dividida em formações florestais, savânicas, campestres, entre outras), as coberturas de uso agropecuário (pastagem, cultura anual, cultural semi-perene, agricultura, mosaico de agricultura e pastagem), e as coberturas para o uso urbano ou de infraestrutura (infraestrutura urbana, áreas com solo exposto, mineração, entre outros) (MAPBIOMAS, 2020).

Para fins do presente estudo, as classes de uso e cobertura do solo apresentadas na iniciativa MapBiomas foram agrupadas em classes de interesse, conforme Tabela 1.

Tabela 1. Classes de uso e cobertura utilizadas no estudo Table 1. Classes of use and coverage used in the study

Classes de uso e cobertura utilizadas no estudo

Formações florestais e naturais

Agropecuária e silvicultura

Área não vegetada

Rio e lago
Classes de uso e cobertura da iniciativa MapBiomas ( $\mathrm{n}^{\circ}$ ID no código de legendas)

Formação florestal (3), Afloramento rochoso (29)

Floresta plantada (9), Pastagem (15), Cultura anual e perene (19), Mosaico de agricultura e pastagem (21)

Infraestrutura urbana (24), Mineração (30), Outra área não vegetada (25)

Rio e lago (33)

Ainda, utilizou-se os arquivos de uso e cobertura do solo do território paulista para os anos de 1985 e 2018, bem como o arquivo de mudança de uso e cobertura do solo para o estado de São Paulo entre 1985 e 2018. O ano de 1985 foi adotado por ser o mais representativo para a situação legal anterior às mudanças ocorridas em 1986, em decorrência da publicação da Resolução CONAMA 004/1985 e da Lei Federal 7511/1986. 
Com a utilização do software livre de geoprocessamento QGIS versão 2.18 - Las Palmas, associado aos complementos GRASSGIS, SAGAGIS e GroupStats, foram extraídos dos dados obtidos da iniciativa MapBiomas, em formato raster, as informações referentes ao município de Jundiaí com uso do polígono contendo os limites do município. Após, os arquivos foram convertidos para formato vetorial.

Na sequência, os arquivos de uso e cobertura do solo para Jundiaí, anos 1985, 2018, e transição 1985-2018 obtidos junto a iniciativa MapBiomas, bem como o arquivo das APPs hídricas obtidos junto a base da FBDS, foram redefinidos para projeção UTM, datum WGS84 fuso $23 \mathrm{~S}$.

Foi realizada, então, a intersecção dos mapas de uso e cobertura do solo para os anos de 1985 e 2018 com as APPs hídricas, e o mapa de transição de uso e cobertura do solo de 1985-2018 com as APPs hídricas, de modo a obter a informação de uso e cobertura de solo e transição do uso e cobertura especificamente nas áreas especialmente protegidas à título de preservação permanente conforme delimitação definida pela legislação vigente.

Com uso da calculadora de campo do software foram calculadas as áreas, em hectares, obtidas a partir destas intersecções, e as planilhas de atributos foram organizadas no complemento GroupStats, e exportadas para o software Excel para análise.

\section{RESULTADOS E DISCUSSÃO}

A partir das análises empreendidas, verifica-se que no território municipal de Jundiaí incide cerca de 8.390 hectares de APPs hídricas delimitadas conforme as diretrizes da legislação vigente, qual seja, a Lei Federal 12.651/2012, o que representa 19,45\% da área do município.

A Figura 2 apresenta o mapa do município de Jundiaí, com a indicação das APPs hídricas e as informações de uso e cobertura do solo para a totalidade do município para o ano de 2018. 


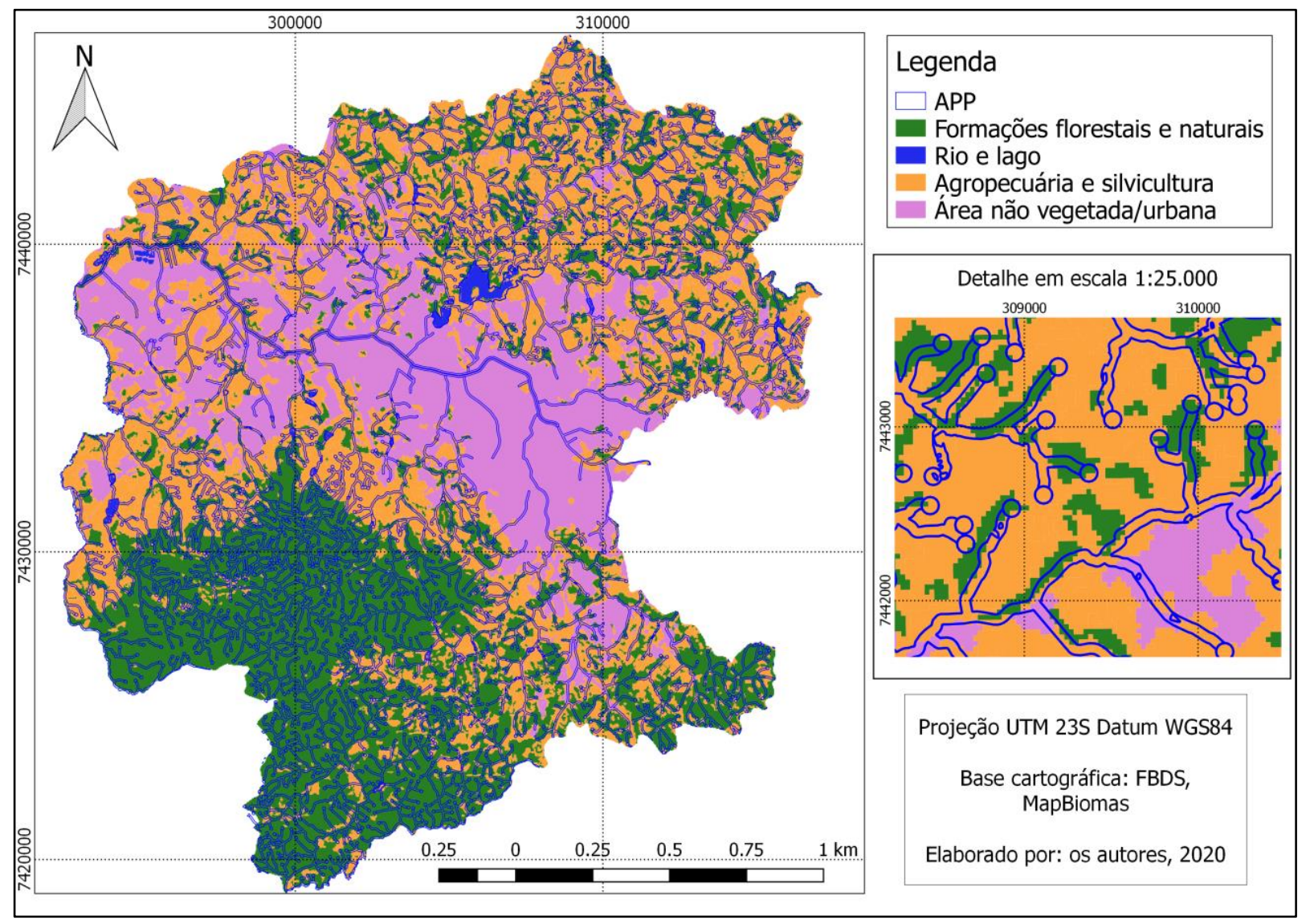

Figura 2. Mapa das APPs hídricas e de uso e ocupação do solo, ano 2018, Jundiaí/SP

Figure 2. Map of riparian APPs and land cover / land use for the year of 2018, Jundiai/SP

Verifica-se do mapa da Figura 2 que a porção sul do município, representada pelo maciço montanhoso protegido da Serra do Japi, apresenta uso e ocupação predominantemente florestal. A porção central do município concentra a ocupação urbana e antrópica, e a porção norte apresenta uso e ocupação predominantemente agropecuária e de silvicultura, com remanescentes florestais bastante fragmentados.

A Tabela 2 apresenta o comparativo de uso e cobertura do solo nas APPs hídricas, delimitada conforme legislação atual, para os anos de 1985 e 2018.

Observa-se que em ambos períodos de análise, a maior parte das APPs está recoberta com cobertura florestal ou com demais formas de vegetação nativa, sendo que de 1985 a 2018 houve um incremento de 242,35 hectares de cobertura florestal/vegetação nativa em APP, ou $5,98 \%$.

Com relação às áreas não vegetadas, que contemplam infraestrutura urbana, mineração e outras áreas não vegetadas, em 1985 estas ocupavam 360 hectares de APPs, passando para 625 hectares em 2018, verificando-se, deste modo, um incremento de 265 hectares, ou $73,78 \%$. 
Tabela 2. Uso e cobertura do solo nas APPs hídricas de Jundiaí em 1985 e 2018

Table 2. Land cover and land use in the Jundiai water APPs in 1985 and 2018

\begin{tabular}{ccccccc}
\hline $\begin{array}{c}\text { Classes de uso e } \\
\text { cobertura utilizadas no } \\
\text { estudo }\end{array}$ & $\begin{array}{c}\text { Área } \\
\text { (hectares) }\end{array}$ & $\%$ & $\begin{array}{c}\text { Área } \\
\text { (hectares) }\end{array}$ & $\%$ & \multicolumn{3}{c}{$\begin{array}{c}\text { Diferença entre 2018 } \\
\text { e 1985 } \\
\text { Área }\end{array}$} & $\%$ \\
\hline $\begin{array}{c}\text { Formações florestais e } \\
\text { naturais }\end{array}$ & $4.048,24$ & 48,25 & $4.290,59$ & 51,14 & 242,35 & 5,98 \\
$\begin{array}{c}\text { Agropecuária e silvicultura } \\
\text { Área não vegetada }\end{array}$ & $3.907,14$ & 46,57 & $3.443,73$ & 41,05 & $-463,41$ & $-11,86$ \\
$\quad 360,14$ & 4,29 & 625,86 & 7,46 & 265,69 & 73,78 \\
$\quad$ Rio e lago & 10,94 & 0,13 & 6,43 & 0,08 & $-4,51$ & $-41,22$ \\
0 - classe de uso/cobertura & 63,86 & 0,76 & 23,51 & 0,28 & $-40,35$ & $-63,18$ \\
\hline não definido & $8.390,32$ & 100,00 & $8.390,12$ & 100,00 & $-0,2$ & $-0,0024$ \\
\hline TOTAL & & & & & & \\
\hline
\end{tabular}

A partir do princípio da temporalidade, entende-se que é possível regularizar parte dos 360 hectares de áreas não vegetadas em APP existentes em 1985, que se mantiveram na mesma condição em 2018. Estas áreas correspondem à infraestrutura urbana (edificações), atividades minerárias, ou demais áreas não vegetadas, como, por exemplo, áreas terraplenadas, que em 1985 estavam regulares (fora de APP), e a partir de 1986 foram inseridas em APP por ocasião das alterações no diploma legal.

A Figura 3 apresenta um mapa ilustrativo do uso e cobertura do solo em 1985 e em 2018 das APPs hídricas de Jundiaí.

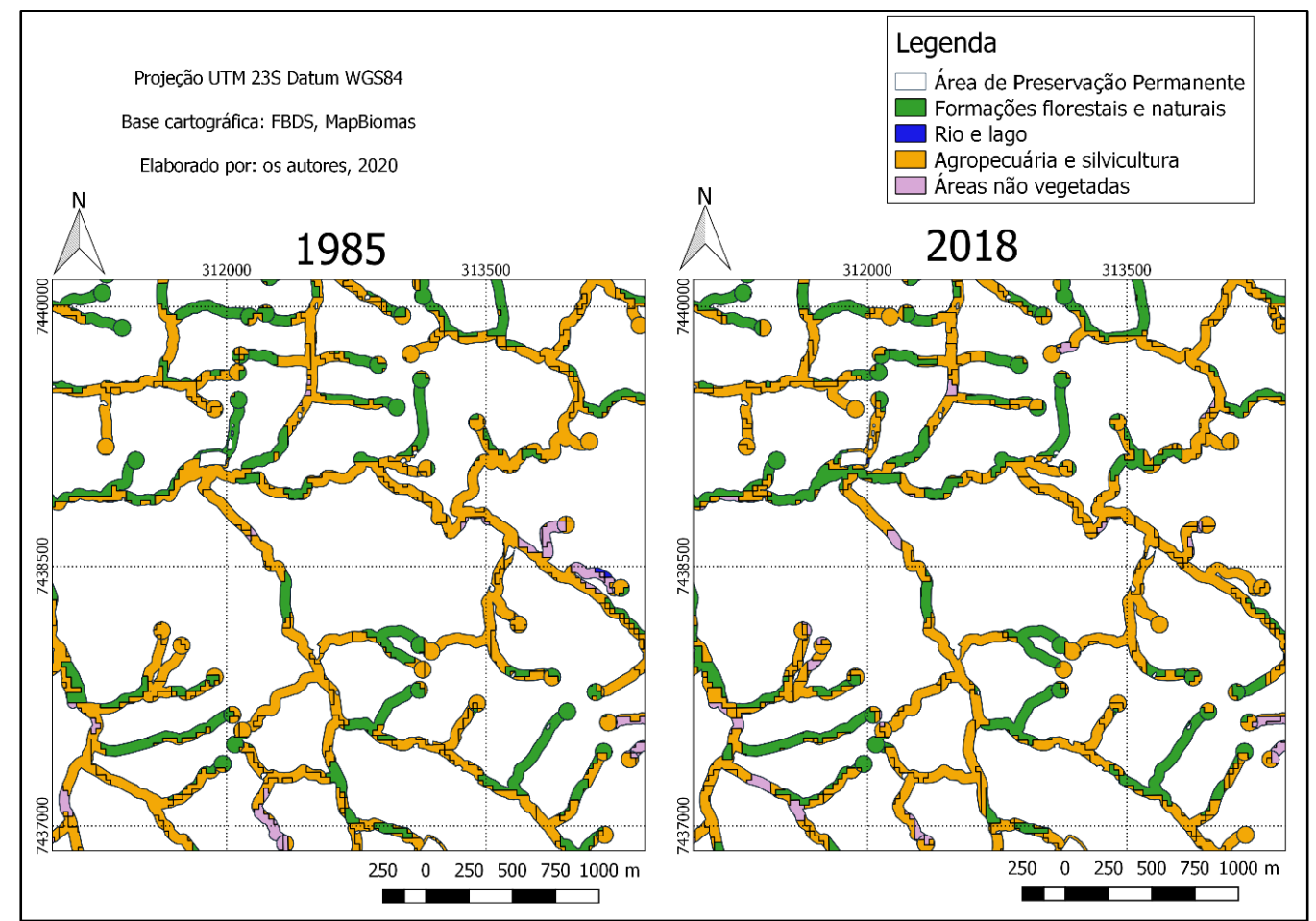

Figura 3. Mapa comparativo - uso e cobertura do solo - APPs hídricas 1985/2018

Figure 3. Comparative map - land use and land cover - water APPs 1985/2018 
Para estimar quanto destas áreas ocupadas em 1985 assim se mantiveram em 2018, foi realizada a análise das informações de mudanças no uso e cobertura do solo entre 19852018, disponibilizadas pela iniciativa MapBiomas, após recorte das APPs hídricas com a utilização das informações disponibilizadas pela FBDS.

Considerando as classes de uso e cobertura utilizadas neste estudo, definidas na Tabela 1, partiu-se do princípio de que tem direito à regularização por meio da temporalidade as mudanças de uso e cobertura observadas entre 1985-2018 descritas na Tabela 3. Cumpre indicar que para esta estimativa foram utilizadas somente as classes de uso referentes à infraestrutura urbana, mineração, e outras áreas não vegetadas, sendo que não foram considerados os usos agropecuários como passíveis de requerer a regularização pela ótica da temporalidade.

Tabela 3. Mudanças de uso e cobertura do solo que tem direito à regularização por temporalidade Códigos de legenda MapBiomas coleção 4.0

Table 3. Changes in land use and land cover that are entitled to regularization by temporality - Legend codes MapBiomas collection 4.0

\begin{tabular}{cc}
\hline $\begin{array}{c}\text { Código de legenda e mudança de uso e cobertura } \\
\text { observada }\end{array}$ & $\begin{array}{c}\text { Mudança observada entre 1985 e 2018 } \\
\text { Área (hectares) }\end{array}$ \\
\hline 2525 - Outra área não vegetada para outra área não \\
vegetada & 0,62 \\
2530 - Outra área não vegetada para mineração & - \\
2524 - Outra área não vegetada para infraestrutura urbana & 3,27 \\
3030 - Mineração para mineração & 0,90 \\
3025 - Mineração para outra área não vegetada & - \\
3024 - Mineração para infraestrutura urbana & - \\
2424 - Infraestrutura urbana para infraestrutura urbana & 298,24 \\
2425 - Infraestrutura urbana para outra área não vegetada & 0,60 \\
2430 - Infraestrutura urbana para mineração & 0,05 \\
TOTAL & $\mathbf{3 0 3 , 6 7}$ \\
\hline
\end{tabular}

Em análise dos dados da Tabela 3, verifica-se que dos 360,14 hectares de APPs ocupadas por "áreas não vegetadas" em 1985, 303,67 hectares $(84,31 \%)$ se mantiveram edificadas/impermeabilizadas/antropizadas em 2018, e, portanto, podem ser regularizáveis pelo princípio da temporalidade. Verifica-se que a infraestrutura urbana é o uso com maior expressão em APPs desde 1985 até a atualidade.

Cotejando as informações das Tabelas 2 e 3, observa-se que dos 625,86 hectares de áreas não vegetadas em APPs em 2018, 303,67 hectares podem ser regulares pelo princípio da temporalidade (48,52\%), o que equivale a $3,62 \%$ do total de APPs existentes no município; ao 
passo que que 322,19 hectares de infraestrutura urbana/área não vegetada/mineração em APP observados em 2018 não são amparados pela temporalidade (51,48\%).

No entanto, é prematuro informar que este montante se refere a ocupações irregulares, visto que neste universo é possível a presença de sistemas viários, infraestruturas de saneamento, dentre outras obras de utilidade pública, interesse social ou baixo impacto ambiental que podem ter sido regularmente implementadas em APP entre 1985 e 2018.

Em uma primeira aproximação, as APPs degradadas passíveis de restauração ecológica em Jundiaí, em 2018, equivalem a 3.765,92 hectares, que é o somatório das APPs ocupadas por agropecuária e silvicultura, e por áreas não vegetadas não regularizáveis pelo princípio da temporalidade, ou $44,89 \%$ do total de APPs do município. Cumpre ressaltar que a aplicação do artigo 61-A da LPVN, que não foi objeto deste estudo, poderá diminuir esta área total de APP passível de restauração ecológica.

A partir do mapeamento de mudanças de uso e cobertura do solo entre 1985-2018, também foi possível analisar a dinâmica de desmatamento e restauração florestal nas APPs de Jundiaí no período estudado, conforme observado na Tabela 4.

Tabela 4. Dinâmica de conservação florestal, desmatamento e restauração florestal nas APPs hídricas de Jundiaí entre 1985-2018

Table 4. Dynamics of forest conservation, deforestation and forest restoration in the Jundiaí water APPs between 1985-2018.

Mudança de uso e cobertura observada

Mudança observada entre 1985 e 2018

1. MANUTENÇÃO DE VEGETAÇÃO Área (hectares)

FLORESTAL/NATIVA

\begin{tabular}{cc}
\hline Conversão de formação florestal para agropecuária & 338,42 \\
Conversão de formação florestal para área não vegetada & 29,49 \\
2. TOTAL CONVERSÃo & $\mathbf{3 6 7 , 9 1}$ \\
\hline Restauração de floresta em área agropecuária & 580,00 \\
Restauração de floresta em área não vegetada & 2,18 \\
Restauração de florestal em rio e lago & 0,76 \\
3. TOTAL RESTAURAÇÃo & $\mathbf{5 8 2 , 9 4}$ \\
\hline
\end{tabular}

Verifica-se que dos 4.290,59 hectares de APP ocupadas por florestas nativas observadas em 2018, 3.704,01 hectares estão nesta condição adequada desde 1985.

A restauração florestal, que ocorreu em 582,94 hectares, superou em 214,97 hectares o desmatamento em APPs no período observado, que foi de 367,91 hectares, indicando uma tendência de melhoria na qualidade florestal das áreas especialmente protegidas, com aumento da cobertura florestal do território, o que corrobora com outros estudos desenvolvidos que vêm 
apontando para um aumento da cobertura florestal no estado de São Paulo, como o de Calaboni et al. (2018).

A Figura 4 apresenta um mapa ilustrativo das mudanças de uso e cobertura do solo observadas nas APPs hídricas de Jundiaí entre 1985 e 2018, com destaque para as áreas desmatadas no período (legenda "conversão de florestas"), para as áreas em que houve restauração de vegetação nativa (legenda "regeneração de florestas"), para as áreas em que a cobertura florestal se manteve (legenda "manutenção de florestas"), e para as áreas passíveis de serem regularizadas pela ótica da temporalidade, isto é, aquelas que se mantiveram edificadas/impermeabilizadas/antropizadas desde 1985. A legenda "outras transições" indicada no mapa é referente as áreas que se mantiveram com atividade agropecuária ou de silvicultura no período, bem como as áreas em que houve transição de áreas não vegetadas para agropecuária ou silvicultura e vice-versa, no período estudado.

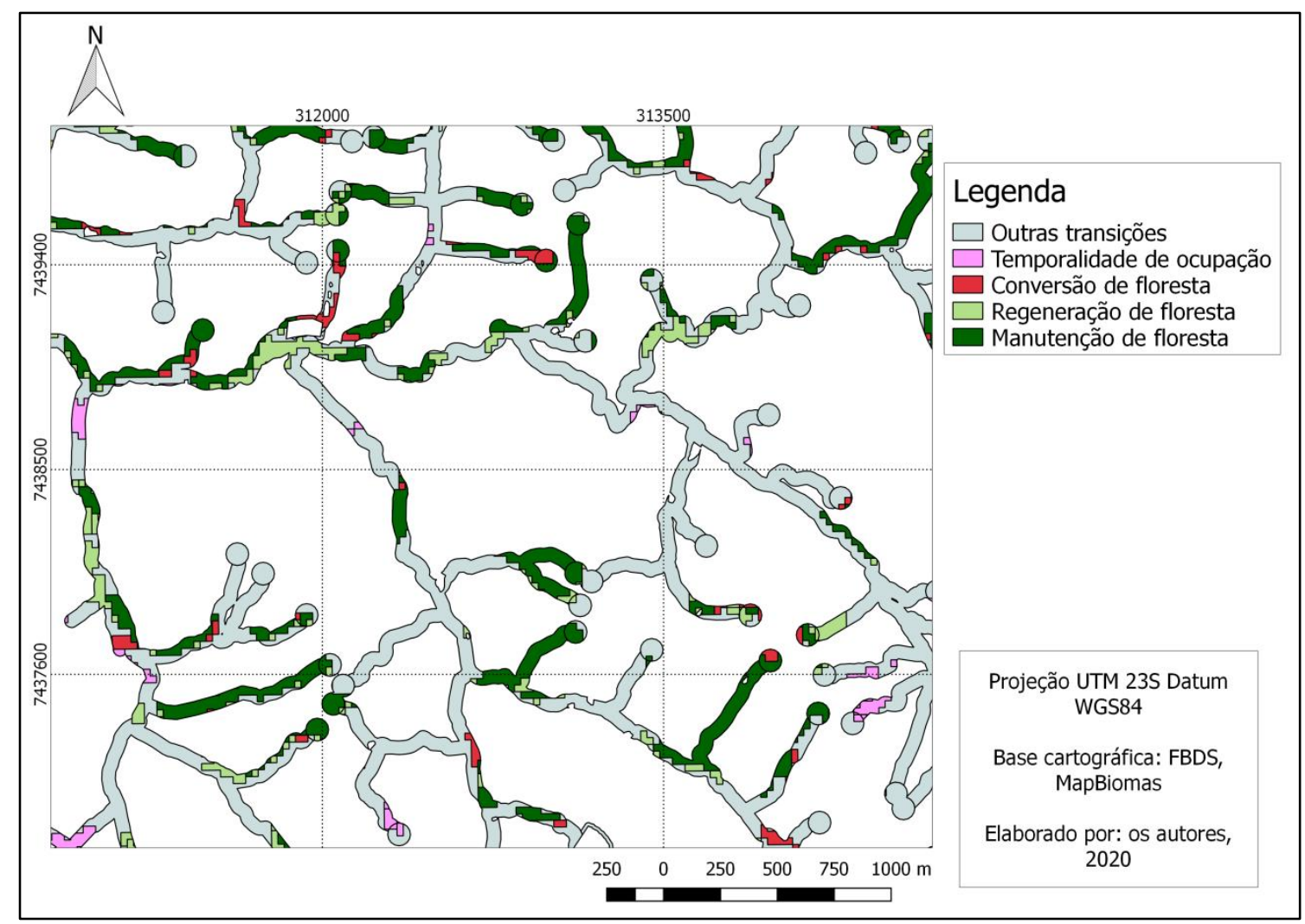

Figura 4. Mapa das mudanças de uso do solo nas APPs hídricas entre 1985 e 2018 Figure 4. Map of land use change in the riparian APPs between 1985 and 2018

Em que pese a localização de Jundiaí entre os municípios de São Paulo e Campinas, o que sugere a existência de uma forte pressão imobiliária e de urbanização, verifica-se que na série histórica de 1985-2018 a urbanização/industrialização foi responsável pela conversão de 29,49 hectares de florestas em APP, ao passo que a agropecuária respondeu por 338,42 hectares desmatados em APP, indicando que os usos agropecuários são os principais vetores 
de desmatamento nas APPs hídricas em Jundiaí, o que corrobora com outros estudos mais amplos, que indicam que a expansão da agropecuária é a principal ameaça ás florestas tropicais em diversas regiões do planeta (DE SY et al., 2019). Também são as classes de agropecuária as que mais cederam áreas para restauração florestal em APPs no período, o que sugere que as ações de comando e controle ou enforcement em relação à aplicação da legislação florestal, associado a políticas de incentivo à restauração florestal de áreas especialmente protegidas, vêm surtindo algum efeito nas últimas três décadas no território estudado.

Os resultados obtidos e a metodologia aplicada no presente trabalho podem auxiliar os órgãos competentes de gestão e licenciamento ambiental na identificação de usos (ir)regulares em APPs, bem como na mensuração do universo de APPs degradadas e disponíveis para restauração florestal. Neste sentido, pesquisas futuras poderão complementar este estudo com a modelagem do montante de APPs cuja restauração fica isentada pela aplicação das disposições transitórias da LPVN, em especial o artigo 61-A.

Considerando que o presente estudo foi desenvolvido com base em dados secundários disponibilizados ao público pela iniciativa MapBiomas e pela FBDS, cujos repositórios apresentam dados para todo o território brasileiro, avalia-se que o itinerário metodológico aqui descrito pode ser replicado por outros pesquisadores em outros municípios do estado de São Paulo ou de outros estados brasileiros.

Avalia-se que a continuidade deste trabalho poderá, em um primeiro momento, abordar os demais municípios do aglomerado urbano de Jundiaí ou da região administrativa de Campinas, de modo a verificar se os municípios do entorno apresentam padrão semelhante de ocupação em APP e de possibilidades de regularização das ocupações pela via da temporalidade.

Em um segundo momento, outras regiões do estado de São Paulo poderão ser avaliadas sob o enfoque ora apresentado, na perspectiva de avaliar a existência de eventuais diferenças regionais no padrão de ocupação de APPs hídricas.

\section{CONCLUSÕES}

O presente estudo objetivou caracterizar as APPs hídricas do município de Jundiaí, no que se refere às condições de uso e ocupação em 2018 e em 1985, com vistas a identificar o montante de APPs ocupadas por usos antrópicos que podem ser regularizadas pelo princípio da temporalidade, bem como iluminar os processos de manutenção, conversão e regeneração de florestas nestas áreas especialmente protegidas, identificando o universo de APPs degradadas em 2018 passíveis de restauração florestal. 
A partir dos resultados obtidos, conclui-se que dos 8.390 hectares de APPs hídricas existentes, a maior parte - 4.290,59 hectares - estava ocupada por vegetação florestal, e 625,86 hectares estavam ocupados por infraestrutura urbana, mineração ou outras áreas não vegetadas em 2018.

Provavelmente, a existência do maciço montanhoso e florestal da Serra do Japi, com a presença de muitas nascentes e corpos hídricos, na região sul do município, contribui para este resultado. Estudos futuros, comparando Jundiaí com municípios vizinhos, poderão aprofundar esta hipótese e avaliar em que medida a existência da Serra do Japi e os instrumentos de proteção associados contribuem para a manutenção das APPs florestadas.

Dos 625,86 hectares de APPs antropizadas em 2018, o estudo revelou que 303,67 hectares $(48,52 \%)$ podem ser regularizados pela ótica da temporalidade, já que estão antropizadas desde 1985. Este resultado indica que mais da metade das APPs antropizadas em 2018 não comprovam temporalidade frente às alterações da legislação vigente. Também cabe ressaltar que as APPs passíveis de regularização pela temporalidade representam apenas $3,62 \%$ das APPs existentes no município.

As APPs com uso agropecuário ou áreas não vegetadas que não comprovam temporalidade, e que, portanto, são passíveis de restauração ecológica, perfazem 3.765,92 hectares, desconsiderando-se os mecanismos de flexibilização da recomposição florestal em APPs previstos na Lei 12.651/2012. Estudos futuros poderão estimar o impacto da aplicação do artigo 61-A da LPVN no território, de modo a refinar este resultado.

Um resultado relevante obtido no estudo é que de 1985 a 2018 houve incremento líquido de cobertura florestal em APPs de 214,97 hectares, sendo que a restauração florestal foi maior que a supressão de vegetação nativa em APPs verificada no período. Também se constatou que o vetor mais importante de supressão de vegetação nativa em APPs foi a agropecuária, responsável pela conversão de 338,42 hectares de florestas em APPs no período estudado.

Avalia-se que o uso de técnicas simples de geoprocessamento, com tratamento dos dados disponibilizados ao público da iniciativa MapBiomas e da FBDS podem auxiliar os órgãos competentes de gestão e licenciamento ambiental na identificação de usos (ir)regulares em APPs, na identificação de áreas prioritárias de restauração florestal, na verificação dos principais vetores de conversão de uso do solo, dentre outras análises pertinentes para as rotinas de licenciamento e gestão ambiental.

\section{REFERÊNCIAS}

AGUIAR, R; ENDRES, J.M.; TAYLOR, C.; EVANS, S. Public Conservation Policies on Private Land: A Case Study of the Brazilian Forest Code and Implications for the Agro-Industry Sector. Pace Environmental Law Review, Nova lorque, v. 34, n.2, p.1-54, 2017. 
AGUJARO, L.F., COLLAÇO, J.F.L., PINTO, A.G. O regramento ambiental de parcelamento do solo como instrumento para a Cidade Saudável no estado de São Paulo. Labor \& Engenho, Campinas, v.12, n.4, p.519-524, 2018.

ARAÚJO, L.S. Análise da expansão urbana e implicações nas Áreas de Preservação Permanente com auxílio de geotecnologias no município de Indaiatuba (SP). Campinas, 2015, 99p. Monografia (Graduação em geografia) - Instituto de Geociências da Universidade Estadual de Campinas, Campinas, 2015.

AZEVEDO, R.E.S. E OLIVEIRA, V.P.V. Reflexos do novo Código Florestal nas Áreas de Preservação Permanente urbanas. Desenvolvimento e Meio Ambiente, Curitiba, v.29, p.71-91, 2014.

BRASIL. Lei Federal ํo 4.771 de 15 de setembro de 1965. Institui o novo Código Florestal. 1965. Disponível em: http://www.planalto.gov.br/ccivil_03/leis/L4771.htm. Acesso em: 23 jan.2020.

BRASIL. Resolução CONAMA 004 de 18 de setembro de 1985, publicada no Diário Oficial da União em 20.01.1986. Dispõe sobre definições e conceitos sobre Reservas Ecológicas. 1986a. Disponível em: http://www2.mma.gov.br/port/conama/legiabre.cfm?codlegi=21. Acesso em: 23 jan.2020.

BRASIL. Lei Federal no 7.511 de 07 de julho de 1986. Altera dispositivos da Lei no 4.771, de 15 de setembro de 1965, que institui o novo Código Florestal. 1986b. Disponível em: http://www.planalto.gov.br/ccivil_03/leis/L7511.htm. Acesso em: 23 jan.2020.

BRASIL. Lei Federal no 7.803 de 18 de julho de 1989 . Altera a redação da Lei no 4.771, de 15 de setembro de 1965, e revoga as Leis nos 6.535, de 15 de junho de 1978, e 7.511, de 7 de julho de 1986. 1986. Disponível em: http://www.planalto.gov.br/ccivil_03/Leis/L7803.htm. Acesso em: 23 jan.2020.

BRASIL. Lei Federal oㅜ 12.651 de 25 de maio de 2012. Dispõe sobre a proteção da vegetação nativa, altera as Leis nำ 6.938, de 31 de agosto de 1981, 9.393, de 19 de dezembro de 1996, e 11.428, de 22 de dezembro de 2006; revoga as Leis nos 4.771, de 15 de setembro de 1965, e 7.754, de 14 de abril de 1989, e a Medida Provisória no 2.166-67, de 24 de agosto de 2001; e dá outras providências. 2012. Disponível em: http://www.planalto.gov.br/ccivil 03/ Ato20112014/2012/Lei/L12651.htm. Acesso em: 23 jan.2020.

BRASIL. Lei Federal o 12.727 de 17 de outubro de 2012. Altera a Lei no 12.651, de 25 de maio de 2012, que dispõe sobre a proteção da vegetação nativa; altera as Leis no s 6.938, de 31 de agosto de 1981, 9.393, de 19 de dezembro de 1996, e 11.428, de 22 de dezembro de 2006; e revoga as Leis no s 4.771, de 15 de setembro de 1965, e 7.754, de 14 de abril de 1989, a Medida Provisória no 2.166-67, de 24 de agosto de 2001, o item 22 do inciso II do art. 167 da Lei no 6.015, de 31 de dezembro de 1973, e o $§ 2^{\circ}$ do art. $4^{\circ}$ da Lei $n^{\circ} 12.651$, de 25 de maio de 2012. Disponível em: http://www.planalto.gov.br/ccivil_03/_ato2011-2014/2012/lei/L12727.htm. Acesso em: 28 abr.2020.

BRASIL. Decreto Federal o 7.830 de 17 de outubro de 2012. Dispõe sobre o Sistema de Cadastro Ambiental Rural, o Cadastro Ambiental Rural, estabelece normas de caráter geral aos Programas de Regularização Ambiental, de que trata a Lei no 12.651, de 25 de maio de 2012, e dá outras providências. Disponível em: http://www.planalto.gov.br/ccivil_03/_Ato20112014/2012/Decreto/D7830.htm Acesso em: 28 abr.2020. 
CALABONI, A., TAMBOSI, L.R., IGARI, A.T., FARINACI, J.S., METZGER, J.P., URIARTE, M. The forest transition in São Paulo, Brazil: historial patterns and potential drivers. Ecology and Society, Atlanta, v.24, n.4, np, 2018.

DE SY, V., HEROLD, M., ACHARD, F., AVITABILE, V., BACCINI,A., CARTER, S., CLEVERS, J.G.P.W., LINDQUIST, E., PEREIRA, M., VERCHOT, L. Tropical deforestation drivers and associated carbon emission factors derived from remote sensing data. Environmental Research Letters, Amsterdã, v. 14, p. 1-14, 2019.

FUNDAÇÃO BRASILEIRA PARA O DESENVOLVIMENTO SUSTENTÁVEL (FBDS). Mapeamento em Alta Resolução dos Biomas Brasileiros: arquivos vetoriais, metadados e metodologia. 2018. Disponível em: www.geo.fbds.org.br. Acesso em: 23 jan.2020.

LUCON, T.N., PRADO FILHO, J.F., SOBREIRA, F.G., BOJIKIAN, C.T. Análise das Áreas de Preservação Permanente do perímetro urbano de Ouro Preto (MG). Revista da Sociedade Brasileira de Arborização Urbana Piracicaba, v.6, n.4, p.107-124, 2011.

MAPBIOMAS - Projeto de Mapeamento Anual da Cobertura e Uso do Solo no Brasil. Coleção 4.0. Disponível em: http://mapbiomas.org/. Acesso em: 23 jan.2020.

MORELLATO, L.P.C. (Org.). História Natural da Serra do Japi: ecologia e preservação de uma área florestal no Sudeste do Brasil. Unicamp/Fapesp, 1992. 321p.

PRADELLA, D.L.P., BUENO, LM.M. Expansão urbana em UC de uso sustentável: conflitos entre a política local e o interesse regional. Revista Nacional de Gerenciamento de Cidades, Tupã, v.5, n.33, p.35-48, 2017.

REZENDE, C. L.; SCARANO, F.R.; ASSAD, E. D.; JOLY, C.A.; METZGER, J.P.; STRASSBURG, B.B.N; TABARELLI, M.; FONSECA, G.A.; MITTERMEIER, R.A. From hotspot to hopespot: An opportunity for the Brazilian Atlantic Forest. Perspectives in Ecology and Conservation, Amsterdã, v. 16, p. 208-2014, 2018.

SCHMIDT, K., MARTÍN-LOPEZ, B., PHILLIPS, P.M., JULIUS, E., MAKAN, N., WALZ, A. Key landscape features in the provision of ecosystem services: insights for management. Land Use Policy, Amsterdã, v. 82, p.353-366, 2019.

SEADE. Fundação Sistema Estadual de Análise de Dados. Informações dos Municípios Paulistas. Disponível em: http://www.imp.seade.gov.br Acesso em: 28 abr.2020.

SILVA, H.R.O., GUIMARÃES, S.C.P., OLIVEIRA, L.B. O uso do geoprocessamento na espacialização e avaliação das Áreas de Preservação Permanente: cidade de Porto Velho - RO. Confins (online), São Paulo, n. 30, np, 2017.

SILVA NETO, J.C.A., ALEIXO, N.C.R. Análise temporal da incompatibilidade das Áreas de Preservação Permanente fluviais e uso da terra na cidade de Manaus - Amazonas - Brasil. Revista Nacional de Gerenciamento de Cidades, Tupã, v.7, n.45, p.64-79, 2019.

TAMBOSI, L.R., VIDAL, M.M., FERRAZ, S.F.B., METZGER, J.P. Funções eco-hidrológicas das florestas nativas e o Código Florestal. Estudos Avançados, São Paulo, v.29, n.84, p. 151-162, 2015.

TANIWAKI, R.H., FORTE, Y.A., SILVA, G.O., BRANCALION, P.H.S., COGUETO, C.V., FILOSO, S. FERRAZ, S.F.B. The Native Vegetation Protection Law of Brazil and the challenge for firstorder stream conservation. Perspectives in Ecology and Conservation, Amsterdã, v.16, n.1, p.49-53, 2018. 